\title{
High Tuberculosis Disease Burden among Indigenous People of the Paraguayan Chaco and Associated Community Characteristics, 2002-2004: An Ecological Study
}

\author{
Amanda VanSteelandt, ${ }^{1}$ Ana Magdalena Hurtado, ${ }^{1}$ Miriam Rolón, ${ }^{2}$ \\ Antonieta Rojas de Arias, ${ }^{2}$ and Juan Carlos Jara ${ }^{3}$ \\ ${ }^{1}$ School of Human Evolution and Social Change, Arizona State University, Tempe, AZ 85287-2402, USA \\ ${ }^{2}$ Centro para el Desarrollo de la Investigación Científica, 1255 Asunción, Paraguay \\ ${ }^{3}$ National Institute of Respiratory and Environmental Diseases (INERAM), Ministry of Health, Asunción, Paraguay \\ Correspondence should be addressed to Amanda VanSteelandt; alvanste@asu.edu
}

Received 25 June 2015; Accepted 10 November 2015

Academic Editor: Jaume Marrugat

Copyright ( 92015 Amanda VanSteelandt et al. This is an open access article distributed under the Creative Commons Attribution License, which permits unrestricted use, distribution, and reproduction in any medium, provided the original work is properly cited.

\begin{abstract}
Indigenous populations are generally reported to suffer greater active tuberculosis (TB) disease burden. The objective of this study was to examine ecological associations between cases of active adult and pediatric TB reported from 2002 to 2004 and community characteristics in indigenous communities of the Paraguayan Chaco. Adult and pediatric models were examined by negative binomial and Poisson GLM regression, respectively. Active TB prevalence in indigenous people was eight times higher than the nonindigenous population. Communities with a health post were more than twice as likely to report active adult TB $(\mathrm{RR}=2.07,95 \%$ confidence interval (CI) [1.14-3.83], and $p<0.05)$. Each additional average year of education in the community was associated with nearly $50 \%$ less likelihood of active pediatric TB $(\mathrm{RR}=0.53,95 \%$ CI [0.38-0.73], and $p<0.001)$. Although nonsignificant, the presence of nonindigenous community members had a strong protective association in both the adult $(\mathrm{RR}=$ $0.56,95 \% \mathrm{CI}[0.30-1.03]$, and $p=0.06)$ and pediatric models $(\mathrm{RR}=0.64,95 \% \mathrm{CI}[0.34-1.14]$, and $p=0.14)$. These results reinforce the importance of increasing epidemiologic surveillance and investigating the social determinants of TB disease among vulnerable indigenous populations.
\end{abstract}

\section{Introduction}

A review of published data on TB disease burden in indigenous populations worldwide found that, in most cases, indigenous populations have higher rates of active TB disease than nonindigenous populations $[1,2]$. These findings are consistent with growing evidence on health disparities between indigenous and nonindigenous people worldwide; across regions, macrolinguistic families, and countries, disease burden and disability rates are higher among the former when compared to their most underprivileged neighbors [2$4]$.

In this study, we describe the excess burden of $\mathrm{TB}$ in indigenous communities in the Chaco and we attempt to isolate risk factors for $\mathrm{TB}$ among indigenous communities that may contribute to excess TB indigenous rates in Paraguay, and elsewhere, using accessible national census data. The significance of choosing to mine these accessible public data is twofold: (a) indigenous communities are vulnerable populations and (b) primary research on infectious diseases in remote, linguistically and culturally diverse native communities is extremely challenging.

Tuberculosis has two types of risk factors: proximate risk factors and upstream determinants [2]. Proximate risk factors can either (1) increase potential for exposure and infection, such as crowding, poorly ventilated housing, or high prevalence of untreated TB in the community, or (2) promote the transition from latent infection to active disease 
by impairing the host immune system, such as malnutrition, coinfections (particularly HIV), smoking, air pollution from solid fuels, alcohol abuse, and diabetes [2, 4]. The upstream determinants of $\mathrm{TB}$ are poverty and other markers of low socioeconomic status that are associated with greater exposure to the proximate risk factors for TB and exacerbate them in complex ways [2].

The health situation of indigenous people is comparable to the world's poorest populations, but with the additional burdens of social and cultural marginalization, geographic and cultural barriers to accessing health services, and, in some areas, appropriation of land and natural resources [5, 6]. In addition to the risk factors and determinants previously described, some studies have identified risk factors specific to particular indigenous populations, including work in particular industries [7], work-related migration [8], and inequalities in access to health services [9].

This paper investigates community characteristics associated with active tuberculosis disease in indigenous communities of the Paraguayan Chaco, using the most recent census data for these communities and prevalence data from the National Tuberculosis Program from 2002 to 2004. The paper presents separate models of adult and pediatric TB, in recognition that the clinical presentation and progression of TB differs across childhood and adulthood. The number of pediatric TB cases typically indicates recent community transmission and thus the effectiveness of TB control programs [10]. In addition, the TB burden of Chacoan indigenous communities is compared with the nonindigenous population in the Chaco and with other indigenous groups worldwide.

\section{Materials and Methods}

2.1. Study Population. The Chaco is a semiarid ecosystem that extends west from the Paraguay River and makes up approximately $60 \%$ of Paraguay's territory. In 2002, the Chaco had a total estimated population of 138,760 , of which 42,964 (31.0\%) were indigenous [11]. The region is sparsely populated with less than 1 person per square kilometer. The Chaco is home to 13 indigenous ethnic groups belonging to five linguistic families, but these communities share similar social organizations and subsistence practices [12]. Indigenous people in the Chaco live mostly by subsistence agriculture and wage labor, and hunting and gathering are supplementary to these activities. Periodic droughts and flooding lead to shortages of food and water in indigenous communities and there is a high rate of poverty; in 2002, $73.2 \%$ of urban and $90.3 \%$ of rural households in the Chaco had at least one Unsatisfied Basic Need (housing quality, sanitation infrastructure, access to education, or capacity for subsistence) [13].

2.2. Tuberculosis Control Program. The Tuberculosis Control Program in Paraguay was implementing the DOTS (Directly Observed Therapy-Short Course) treatment strategy from 2002 to 2004 and had limited coverage [14]. In 2002, 10\% of the population lived in a DOTS area [15], and by 2004 the program had expanded to $27 \%$ of the Paraguayan population
[14]. It is unclear how much of the DOTS coverage was in the Chaco region; thus, we are unable to control for the effect of DOTS treatment on TB rates. The case detection rate for TB in all forms was relatively regular in Paraguay from 1995 and 2004 [16], but there was an increase in smear positive cases of pulmonary TB between 2003 and 2004 that could be attributed to increased detection activities.

Between 2002 and 2004, foreign or local missionaries, nongovernmental organization nurses, anthropologists, rural health facility-based surveillance workers, community health care workers, and private medical missions reported active cases of TB to the Ministry of Health $(\mathrm{MoH})$ by submitting requests for $\mathrm{TB}$ treatment with results of diagnosis at local health posts, clinics, or hospitals. The requests required minimally a $\mathrm{MoH}$ health care official's description of symptoms where a patient had "night sweats" in combination with chronic cough and rapid weight loss. Sputum analyses or lung X-rays were expected in regions where $\mathrm{MoH}$ clinics or hospitals had the necessary equipment and personnel (Hurtado, TB Field Notes 1990-2006). Extrapulmonary cases of active TB among indigenous persons of the Chaco were diagnosed at the Yalve Sanga Hospital in the Chaco and the Max Boettner Hospital in Asunción. These cases are very difficult to detect and underdiagnosed.

2.3. Data Sources. A comprehensive database of indigenous communities and their characteristics in the departments of Boquerón, Presidente Hayes, and Alto Paraguay was compiled from the 2002 Atlas of Indigenous Communities in Paraguay [17]. The data for the Atlas, a compendium of demographic and socioeconomic information about ethnic groups and communities, were collected during the 2002 National Indigenous Census of Population and Households in Paraguay. Population sizes of the communities were broken into population under 15 years and population 15 years and older to divide the pediatric and adult populations of each community.

Variables from the Atlas were chosen based on how well they operationalized potential risk factors for TB (see Table 2). Distance from the capital of the department (in hundreds of kilometers) was used as a proxy for remoteness of the community. Remoteness represents the degree of isolation of a community as well as potential difficulty in accessing healthcare and other infrastructures. The presence or absence of a health post in the community is a measure of local healthcare access, and as the health posts are charged with reporting TB cases to the National TB Program, they also correspond to a greater likelihood of detection (detection bias). The potential for coinfections, particularly of the gastrointestinal form, was included as the percentage of community members whose primary water source is surface water. Crowding was measured as the average number of people per household in the community. Ideally, we would want to know the number of people per compartment or compartment size (i.e., square or cubic meters) in the household, but this level of detail is not available in the Atlas. The majority of houses in Chacoan indigenous communities are built of split palm trunks and/or 
adobe, wattle, and daub; they are similar in size and rarely have more than one room [12].

Four variables were included as measures of socioeconomic status (SES). While most homes are constructed as previously described, some are of a more permanent construction type. The first SES variable is the percentage of households with sturdier construction (generally, brick walls and a metal roof, described as casa in the Atlas) [17]. The second SES variable is the percentage of community members engaged in wage labor. The third is level of education, which was operationalized by the average years of study of adult community members. The fourth variable is whether or not the community own their own land, which is indicative of SES as well as the infrastructure available to the community.

The final variable included in the model is the presence or absence of nonindigenous community members, a marker for the degree of social integration with general Paraguayan society. The presence of nonindigenous community members is indicative of two integrative processes: nonindigenous NGO workers, missionaries, teachers, or healthcare workers who work and live in the community and/or nonindigenous spouses who marry into indigenous families. Anecdotally, households with nonindigenous community members in the Chaco tend to have better housing and greater material wealth; thus, nonindigenous community composition may also be a proxy for SES.

The last published indigenous population census was conducted in 2002; therefore, we selected TB data from that period for analysis. The National TB Program and Department of Statistics for the Ministry of Public Health and Social Wellbeing in Paraguay provided data on the locations and ages of all cases of active tuberculosis reported to them by health posts, clinics, and hospitals from 2002 to 2004 . We estimated TB period prevalence per 100,000 people as follows:

$$
\begin{aligned}
& \text { TB period prevalence } \\
& =\frac{\text { new and existing cases of TB from 2002-2004*10 }}{\text { population in } 2002} .
\end{aligned}
$$

For comparison with $\mathrm{TB}$ prevalence in other indigenous populations [8, 18-24], the TB prevalence per 100,000 for just 2002 was also calculated. (The year 2002 was selected because it coincided with the collection of the population data; the prevalence of TB in the indigenous population in 2002 was lower than in 2003 and 2004.)

From this database, 532 cases of active tuberculosis in the 105 Chacoan communities identified as indigenous by the Atlas were extracted for analysis. Most TB cases were reported at the community level, but when TB cases were reported for a subdivision (aldea) of a community the subdivision was treated as an independent community. For these cases we subtracted the population of the independently reported subdivision from the community totals. The reported TB cases were sorted into six age groups: $<1$ year, 1-4 years, 514 years, $15-19$ years, $20-49$ years, and 50 or more years, and we separated these into $<15$ years and 15 years and older to divide the pediatric and adult TB cases.
2.4. Data Cleaning. In some instances, the names of the communities reported in the National TB Program data were not easy to connect with the names given in the Atlas because a community is known by multiple names or there were multiple communities with similar names. Most of these problems could be resolved when the location and primary ethnic group of the community were further investigated in the INDI database [25], but a few were resolved due to the authors' firsthand knowledge of the communities. One community was excluded from the analysis due to missing data.

2.5. Statistical Analysis. All statistical analyses used R software, version 2.15.2 [26]. Correlations between the predictor variables were examined for potential collinearity and the distribution of these variables across linguistic families and departments was also analyzed (see Supplementary Material available online at http://dx.doi.org/10.1155/2015/841289). Ecological associations between pediatric and adult cases of TB from 2002 to 2004 and community characteristics were examined by Poisson GLM regression and negative binomial GLM regression, respectively, to account for overdispersion in the adult model. The Poisson regression model assumes that the variance and mean are equal, whereas the negative binomial regression model includes a dispersion parameter for a more accurate estimate of the variance and better model fit in cases where variance exceeds the value of the mean (overdispersion) [27]. The model for multivariate analysis included nine main variables extracted from the Atlas and an offset for population (see Table 2). Unadjusted and adjusted risk ratios were calculated from the regression coefficients for each variable in univariate and multivariate models. Odds ratios, which would be more appropriate for a crosssectional study, should be approximately equal to the risk ratios under the rare disease assumption [28]. As we are interested in identifying ecological associations of interest for future research, the multivariate models contained all of the variables to give conservative estimates of effect size in the adjusted risk ratios.

Ethics approval for this study was provided by the Institutional Review Board at Arizona State University.

\section{Results}

The period prevalence of tuberculosis cases from 2002 to 2004 and demographic characteristics of the three departments and five linguistic families in the Chaco are presented in Table 1. The indigenous population in the Chaco is concentrated in the Central Chaco, near the Mennonite colonies, and Lower Chaco, as shown by the greater number of communities located in the Boquerón and Presidente Hayes departments. The majority of the indigenous population belongs to either the Lengua Maskoy or Mataco Mataguay linguistic families. Communities ranged in size from 23 to 3888 individuals.

The active TB period prevalence in indigenous people in the Chaco (1255 TB cases per 100,000, 2002-2004) is eight times greater than the nonindigenous population in 
TABLE 1: Descriptive statistics for TB cases and demographics of indigenous communities of the Chaco by department and linguistic family, 2002-2004.

\begin{tabular}{|c|c|c|c|c|c|c|}
\hline & \multicolumn{3}{|c|}{ TB cases 2002-2004 } & \multirow{2}{*}{$\begin{array}{l}\text { Period prevalence of active TB cases per } \\
100,000 \text { inhabitants, } 2002-2004\end{array}$} & \multirow{2}{*}{$\begin{array}{l}\text { Total population, } 2002 \\
\quad(<15 \text { yrs : } \geq 15 \text { yrs })\end{array}$} & \multirow{2}{*}{$\begin{array}{c}\text { Number of } \\
\text { communities, } 2002\end{array}$} \\
\hline & $<15$ yrs & $\geq 15 \mathrm{yrs}$ & All & & & \\
\hline \multicolumn{7}{|c|}{ Department } \\
\hline Boquerón & 18 & 147 & 165 & 833 & $\begin{array}{c}19807 \\
(7997: 11810)\end{array}$ & 39 \\
\hline Presidente Hayes & 79 & 263 & 342 & 1762 & $\begin{array}{c}19409 \\
(8200: 11209)\end{array}$ & 49 \\
\hline Alto Paraguay & 6 & 19 & 25 & 790 & $\begin{array}{c}3166 \\
(1444: 1722) \\
\end{array}$ & 19 \\
\hline \multicolumn{7}{|c|}{ Linguistic family } \\
\hline Lengua Maskoy & 51 & 246 & 297 & 1553 & $\begin{array}{c}19130 \\
(7683: 11447)\end{array}$ & $\begin{array}{l}52 \text { (5 ethnic } \\
\text { groups) }\end{array}$ \\
\hline Guaicuru & 7 & 31 & 38 & 2663 & $\begin{array}{c}1427 \\
(682: 745)\end{array}$ & 4 (1 ethnic group) \\
\hline Guaraní & 1 & 20 & 21 & 470 & $\begin{array}{c}4469 \\
(1915: 2554)\end{array}$ & 8 (2 ethnic groups) \\
\hline Mataco Mataguay & 39 & 122 & 161 & 1152 & $\begin{array}{c}13972 \\
(5900: 8072)\end{array}$ & $\begin{array}{l}27 \text { (3 ethnic } \\
\text { groups) }\end{array}$ \\
\hline Zamuco & 5 & 10 & 15 & 443 & $\begin{array}{c}3384 \\
(1461: 1923)\end{array}$ & $\begin{array}{l}14 \text { ( } 2 \text { ethnic } \\
\text { groups) }\end{array}$ \\
\hline Total & 103 & 429 & 532 & 1255 & 42382 & 105 \\
\hline
\end{tabular}

TABLE 2: Description of variables selected from the 2002 Atlas of Indigenous Communities in Paraguay [12].

\begin{tabular}{|c|c|c|}
\hline Continuous variables & Description & Mean and standard deviation \\
\hline Crowding & Average number of people per household & $5.72 \pm 1.21$ \\
\hline Education & Average number of years of study & $2.03 \pm 0.91$ \\
\hline House type & Percentage of community members who have permanent houses & $46.7 \pm 32.4$ \\
\hline Remoteness & Distance from the department capital in hundreds of kilometers & $2.36 \pm 1.49$ \\
\hline Surface water usage & $\begin{array}{l}\text { Percentage of community members who use a tajamar or surface water as a } \\
\text { primary water source }\end{array}$ & $58.08 \pm 43.08$ \\
\hline Wage labor & Percentage of community members engaged in wage labor & $43.41 \pm 27.39$ \\
\hline Binary variables & Description & Proportions (yes : no) \\
\hline Health post & Does the community have a health post? (yes/no) & $47(45.2 \%): 57(54.8 \%)$ \\
\hline Land ownership & Does the community own its land? (yes/no) & $65(62.5 \%): 39(37.5 \%)$ \\
\hline Nonindigenous & Are there nonindigenous community members? (yes/no) & $30(28.8 \%): 74(71.2 \%)$ \\
\hline
\end{tabular}

the Chaco (155 TB cases per 100,000, 2002-2004). When the linguistic families are analyzed separately, they range from 2.9 times the nonindigenous prevalence in the Zamuco to 17.1 times the nonindigenous prevalence in the Guaicuru.

When comparing the prevalence of $\mathrm{TB}$ for indigenous groups of the Chaco in 2002 to other indigenous groups worldwide, they fall into the middle range (see Tollefson et al. [1]). When restricting the comparison to Latin America, the prevalence of TB for indigenous groups in the Chaco is on the lower end, but two of the high prevalence studies (among the Panara [23] and Yanomami [24]) were conducted several years earlier (Figure 1).

Descriptive statistics for the predictor variables are presented in Table 2. Indigenous communities in the Chaco are generally remote, an average of $236 \mathrm{~km}$ away from their department capital. On average, these communities had
$5.72( \pm 1.21)$ people per household and $2.03( \pm 0.91)$ years of education. There was large variation in the percentages of permanent houses, surface water usage, and participation in wage labour. Slightly less than half of the communities had their own health post (45.2\%), and most owned their own land $(62.5 \%)$. Nonindigenous community members were present in $28.8 \%$ of communities.

In the negative binomial adult model, having a health post was the only significant association with active TB, while the presence of nonindigenous community members was nearly significant (see Table 3). Holding all else constant, communities with a health post were more than twice as likely to report adult TB $(\mathrm{RR}=2.07,95 \% \mathrm{CI}[1.14-3.83]$, and $p<0.05)$. Communities with nonindigenous community members had $44 \%$ less risk for adult TB $(\mathrm{RR}=0.56,95 \% \mathrm{CI}$ [0.30-1.03], and $p=0.06)$. Years of study and house type 


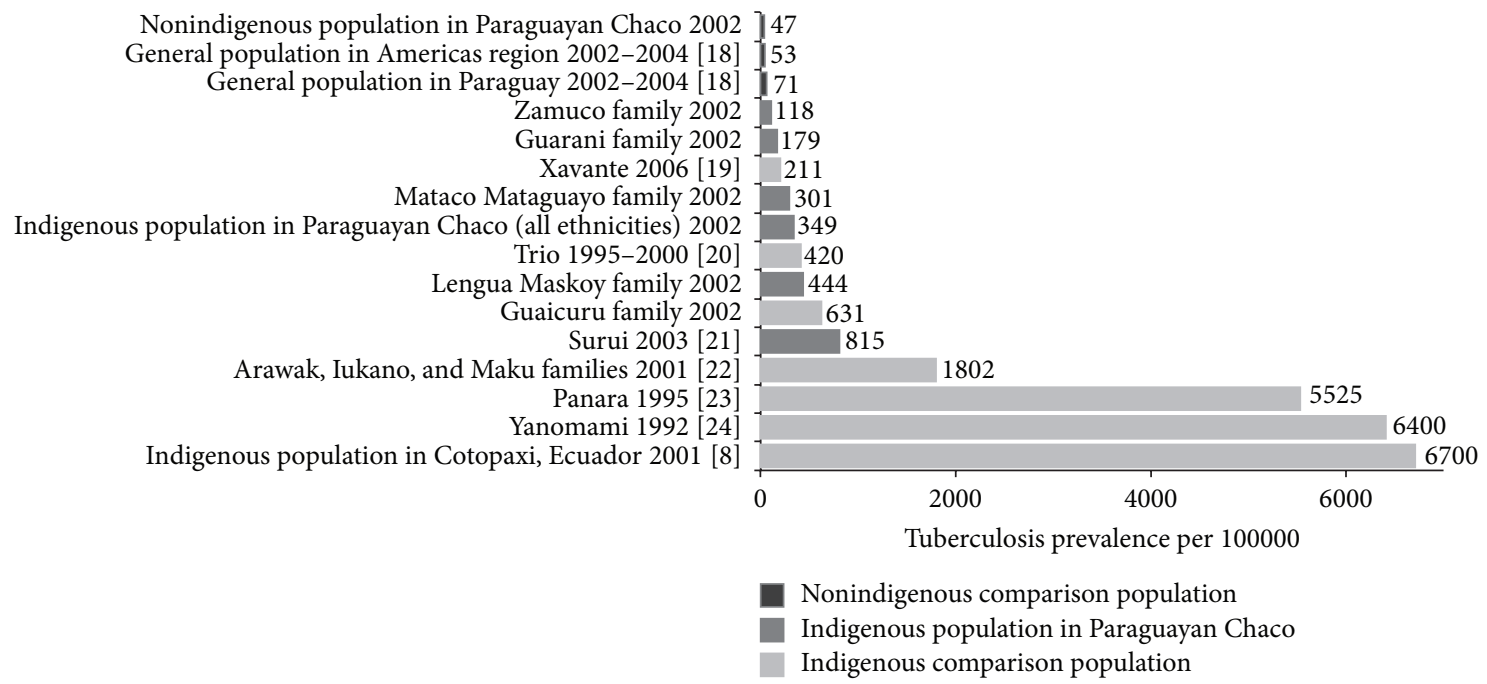

FIgURE 1: Comparison of tuberculosis prevalence in indigenous populations of the Paraguayan Chaco to nonindigenous populations and other Latin American indigenous people. Latin American data were sourced through the Tollefson et al. [1] meta-analysis; original source articles are listed next to the population and year of data collection.

were associated with minor risk reduction for active TB but had wide confidence intervals. Crowding, land ownership, and remoteness were associated with minor risk increases for active TB but had wide confidence intervals. Neither wage labour nor water source was associated with active TB.

In the Poisson pediatric model, years of study were the only significant predictor of active TB (see Table 3). Holding all else constant, each year increase in the average years of education in the community was associated with nearly $50 \%$ less likelihood of reporting pediatric $\mathrm{TB}(\mathrm{RR}=0.53$, 95\% CI [0.38-0.73], and $p<0.001)$. Communities with nonindigenous community members had $36 \%$ less risk for pediatric TB $(\mathrm{RR}=0.64,95 \% \mathrm{CI}[0.34-1.14]$, and $p=0.14)$. Contrary to expectations, increased crowding was associated with a minor reduction in risk for active TB, but this result is nonsignificant. Having a health post was associated with a minor increased risk of active TB, but the confidence interval was large. House type, land ownership, remoteness, wage labour, and water source appeared to have a neutral or no association with active TB.

The goodness-of-fit statistics indicate that both models fit the data well ( $p=0.21$ and $p=0.17$, resp., for the adult and pediatric models).

\section{Discussion}

The data available for this analysis are not ideal measures, but they provide initial insight into a region with a vulnerable population and where limited information is available. The choice of predictor variables for this analysis was limited by the data available in the Atlas. The analysis could be improved with a better measure of material wealth and data on other reported risk factors for TB that were not available, such as the prevalence of smoking, alcohol abuse, and diabetes, the use of solid fuels (indoor air pollution), and food security in Chacoan communities. Using the full complement of potential risk factor variables in the calculation of adjusted risk ratios provides a conservative estimate of which factors are associated with active TB in indigenous communities and require further investigation. It is likely that the data from the National TB Program significantly underestimate the true rate of active TB in the Chaco because we suspect that some number of people die of the disease before they are diagnosed, particularly in the case of extrapulmonary TB.

In the adult model, the presence of a health post in the community was associated with increased risk of active TB disease (see Table 3). TB cases are more likely to be detected where there is a constant healthcare worker presence, and this may explain the strong association. Also, sometimes people from outlying communities move to communities with health posts to receive care and may live with relatives in the community while they complete treatment. Alternatively, health posts may have been built in these communities because they historically reported a higher prevalence of TB.

Interestingly, the presence of nonindigenous community members had a strong protective association against TB in both models, although the effect is only nearly significant in the adult model (see Table 3 ). As nonindigenous community members account for less than $6.9 \%$ of the population in the 30 communities where they are present, except for one outlier community with $25.8 \%$ nonindigenous members, it is unlikely that the effect is simply fewer indigenous people living in the community. The nonindigenous community members may be aid-workers, missionaries, teachers, or healthcare workers who work to improve healthcare and education, and they may improve the capacity of indigenous communities to respond to TB through these channels. However, many teachers and health promoters in indigenous communities are themselves indigenous community members: current DOTS workers in the Chaco are most often indigenous health promoters who are members of the community. Nonindigenous community members may also 
TABLE 3: Models of associations between community characteristics and number of adults and pediatric TB cases in indigenous communities of the Chaco from 2002 to 2004, offset by population.

\begin{tabular}{|c|c|c|c|c|c|c|}
\hline \multirow[b]{2}{*}{ Variable } & \multicolumn{3}{|c|}{ Negative binomial adult model } & \multicolumn{3}{|c|}{ Poisson pediatric model } \\
\hline & $\begin{array}{l}\text { Unadjusted } \\
\text { risk ratio } \\
(95 \% \mathrm{CI}) \\
\end{array}$ & $\begin{array}{l}\text { Adjusted } \\
\text { risk ratio } \\
(95 \% \mathrm{CI}) \\
\end{array}$ & $\begin{array}{c}\text { Adjusted } \\
p \text { value }\end{array}$ & $\begin{array}{l}\text { Unadjusted } \\
\text { risk ratio } \\
(95 \% \text { CI })\end{array}$ & $\begin{array}{l}\text { Adjusted } \\
\text { risk ratio } \\
(95 \% \mathrm{CI})\end{array}$ & $\begin{array}{c}\text { Adjusted } \\
p \text { value }\end{array}$ \\
\hline Crowding & $\begin{array}{c}1.06 \\
(0.87-1.28)\end{array}$ & $\begin{array}{c}1.11 \\
(0.90-1.37)\end{array}$ & 0.34 & $\begin{array}{c}0.86 \\
(0.69-1.06)\end{array}$ & $\begin{array}{c}0.84 \\
(0.65-1.08)\end{array}$ & 0.19 \\
\hline Health post ${ }^{*}$ & $\begin{array}{c}1.49 \\
(0.91-2.45) \\
\end{array}$ & $\begin{array}{c}2.07 \\
(1.14-3.83) \\
\end{array}$ & 0.02 & $\begin{array}{c}0.81 \\
(0.52-1.31) \\
\end{array}$ & $\begin{array}{c}1.15 \\
(0.63-2.19) \\
\end{array}$ & 0.65 \\
\hline House type & $\begin{array}{c}0.99 \\
(0.99-1.00)\end{array}$ & $\begin{array}{c}0.99 \\
(0.99-1.00)\end{array}$ & 0.24 & $\begin{array}{c}0.99 \\
(0.99-1.00)\end{array}$ & $\begin{array}{c}1.00 \\
(0.99-1.01)\end{array}$ & 0.84 \\
\hline Land ownership* & $\begin{array}{c}1.57 \\
(0.93-2.63)\end{array}$ & $\begin{array}{c}1.15 \\
(0.63-2.11)\end{array}$ & 0.63 & $\begin{array}{c}1.07 \\
(0.65-1.86)\end{array}$ & $\begin{array}{c}1.00 \\
(0.55-1.88)\end{array}$ & 1.00 \\
\hline Nonindigenous* & $\begin{array}{c}0.80 \\
(0.48-1.36)\end{array}$ & $\begin{array}{c}0.56 \\
(0.30-1.03)\end{array}$ & 0.06 & $\begin{array}{c}0.49 \\
(0.29-0.81)\end{array}$ & $\begin{array}{c}0.64 \\
(0.34-1.14)\end{array}$ & 0.14 \\
\hline Remoteness & $\begin{array}{c}1.11 \\
(0.95-1.30)\end{array}$ & $\begin{array}{c}1.06 \\
(0.88-1.27)\end{array}$ & 0.53 & $\begin{array}{c}1.20 \\
(1.06-1.37)\end{array}$ & $\begin{array}{c}1.03 \\
(0.87-1.22)\end{array}$ & 0.72 \\
\hline Wage labour & $\begin{array}{c}0.99 \\
(0.98-1.00)\end{array}$ & $\begin{array}{c}1.00 \\
(0.99-1.01)\end{array}$ & 0.95 & $\begin{array}{c}0.99 \\
(0.98-1.01) \\
\end{array}$ & $\begin{array}{c}1.00 \\
(0.99-1.02) \\
\end{array}$ & 0.44 \\
\hline Water source & $\begin{array}{c}1.00 \\
(1.00-1.01)\end{array}$ & $\begin{array}{c}1.00 \\
(1.00-1.01)\end{array}$ & 0.52 & $\begin{array}{c}1.01 \\
(1.00-1.01)\end{array}$ & $\begin{array}{c}1.00 \\
(1.00-1.01)\end{array}$ & 0.17 \\
\hline Years of study & $\begin{array}{c}0.88 \\
(0.66-1.17)\end{array}$ & $\begin{array}{c}0.88 \\
(0.64-1.21)\end{array}$ & 0.41 & $\begin{array}{c}0.50 \\
(0.39-0.65)\end{array}$ & $\begin{array}{c}0.53 \\
(0.38-0.73)\end{array}$ & $<0.001$ \\
\hline
\end{tabular}

Model fit Residual deviance 104.79 on $94 \mathrm{df}$

Goodness-of-fit test for Poisson assumption $\chi^{2}=104.79, p=0.21$
Residual deviance 106.71 on $94 \mathrm{df}$

Goodness-of-fit test for Poisson assumption $\chi^{2}=106.71, p=0.17$

${ }^{*}$ The reference category for binary variables is the absence of the trait.

be spouses who have married into indigenous communities and bring greater material wealth with them. It could also be that people from communities with fewer TB cases are more likely to marry a nonindigenous person. This novel finding merits further investigation but should be interpreted with caution. It would be advisable for follow-up studies to involve indigenous communities in their design and interpretation.

In the pediatric model, the average years of education in the community were associated with decreased reporting of pediatric TB cases (see Table 3). This relationship may be direct or indirect. Higher education levels may increase the ability of community members to identify TB symptoms as well as overcome language barriers and navigate the healthcare system and in this way may support the effectiveness of TB control programs. Higher education levels may also indirectly reduce exposure to the proximate risk factors for TB by improving access to better paying jobs and economic security, for example.

The lack of statistical significance for some of the determinants included in the model may be due to determinants that are too similar across indigenous communities, and further analysis comparing indigenous and nonindigenous people of the Chaco may reveal other important determinants of $\mathrm{TB}$ shared across indigenous communities. Unfortunately, the Atlas includes only indigenous community characteristics, and similar comparators were not available for nonindigenous communities.

The TB burden in indigenous communities of the Chaco region fits well within the range of variation in indigenous TB burden worldwide and further supports evidence that indigenous people generally suffer greater disease burden than nonindigenous people [1]. When compared with other South American indigenous groups (Figure 1), the burden of disease in Chacoan indigenous groups is lower than that experienced by their indigenous neighbors. Notably, some of these other studies of South American indigenous groups involved more proactive case finding, while the active TB rates calculated in this study came from the usual reporting activities of Paraguay's National TB Program. A case detection effort dedicated to indigenous communities would undoubtedly reveal an even higher TB burden in the Chaco.

\section{Conclusions}

While the national incidence and prevalence of active TB in Paraguay are in the low range by international standards, the indigenous population in the Chaco suffers TB incidences and prevalence comparable to high-burden countries. TB prevention and control efforts are better served by focusing 
on specific at-risk subpopulations, like the indigenous, rather than national, statistics that dilute the scale of the problem in these communities. The data support significant associations between healthcare access and active TB disease in adults and education and active TB in children. In recent years the National TB Program in Paraguay has increased its attention in indigenous communities, and while some government and NGO initiatives are tackling the social determinants of health in indigenous communities, much work remains to be done [29]. The protective effect of a nonindigenous presence in the community is a novel finding that merits further investigation. This study provides initial clues for the disparity in active TB prevalence between indigenous and nonindigenous populations in the Chaco, but better surveillance data are needed on known risk factors and upstream determinants for $\mathrm{TB}$ in these vulnerable communities.

\section{Conflict of Interests}

The authors declare that there is no conflict of interests regarding the publication of this paper.

\section{Authors' Contribution}

The data were acquired by Juan Carlos Jara, Ana Magdalena Hurtado, Miriam Rolón, and Antonieta Rojas de Arias, data cleaning was performed by Amanda VanSteelandt and Miriam Rolón, data analysis was performed by Amanda VanSteelandt with guidance from Ana Magdalena Hurtado, drafting of the paper was done by Amanda VanSteelandt, and all authors edited the paper and approved the final version.

\section{Acknowledgments}

The authors wish to thank the National Tuberculosis Program in Paraguay, the Department of Statistics for the Ministry of Public Health and Social Wellbeing, and the Boquerón and Presidente Hayes Health Regions in Paraguay. This work was supported by the Wenner Gren Foundation (Grant no. 8462); the National Science Foundation (Grant no. 1026520); Sigma Xi: The Scientific Research Society; and Arizona State University's School of Human Evolution and Social Change and Graduate and Professional Student Association.

\section{References}

[1] D. Tollefson, E. Bloss, A. Fanning, J. T. Redd, K. Barker, and E. McCray, "Burden of tuberculosis in indigenous peoples globally: a systematic review," International Journal of Tuberculosis and Lung Disease, vol. 17, no. 9, pp. 1139-1150, 2013.

[2] K. Lönnroth, E. Jaramillo, B. G. Williams, C. Dye, and M. Raviglione, "Drivers of tuberculosis epidemics: the role of risk factors and social determinants," Social Science \& Medicine, vol. 68, no. 12, pp. 2240-2246, 2009.

[3] M. Gracey and M. King, "Indigenous health part 1: determinants and disease patterns," The Lancet, vol. 374, no. 9683, pp. 65-75, 2009.
[4] P. Narasimhan, J. Wood, C. R. MacIntyre, and D. Mathai, "Risk factors for tuberculosis," Pulmonary Medicine, vol. 2013, Article ID 828939, 11 pages, 2013.

[5] C. Stephens, J. Porter, C. Nettleton, and R. Willis, "Disappearing, displaced, and undervalued: a call to action for Indigenous health worldwide," The Lancet, vol. 367, no. 9527, pp. 2019-2028, 2006.

[6] M. King, A. Smith, and M. Gracey, "Indigenous health part 2: the underlying causes of the health gap," The Lancet, vol. 374, no. 9683 , pp. 76-85, 2009.

[7] F. P. C. Sacchi, M. G. Croda, A. O. Estevan, A. I. Ko, and J. Croda, "Sugar cane manufacturing is associated with tuberculosis in an indigenous population in Brazil," Transactions of the Royal Society of Tropical Medicine and Hygiene, vol. 107, no. 3, pp. 152 $157,2013$.

[8] N. C. Romero-Sandoval, O. F. Flores-Carrera, H. J. SánchezPérez, I. Sánchez-Pérez, and M. M. Mateo, "Pulmonary tuberculosis in an indigenous community in the mountains of Ecuador," International Journal of Tuberculosis and Lung Disease, vol. 11, no. 5, pp. 550-555, 2007.

[9] A. Levino and R. M. de Oliveira, "Tuberculosis among the Indian population in São Gabriel da Cachoeira, Amazonas State, Brazil," Cadernos de Saude Publica, vol. 23, no. 7, pp. 17281732, 2007.

[10] B. J. Marais, “Childhood tuberculosis: epidemiology and natural history of disease," Indian Journal of Pediatrics, vol. 78, no. 3, pp. 321-327, 2011.

[11] Dirección General de Estadística, "Encuestas y Censos: II Censo Nacional Indígena de Población y Viviendas," 2002, (Spanish), http://www.dgeec.gov.py/.

[12] J. Renshaw, The Indians of the Paraguayan Chaco: Identity \& Economy, University of Nebraska Press, Lincoln, Neb, USA, 2002.

[13] Dirección General de Estadística, Encuestas y Censos: Atlas de Necesidades Básicas Insatisfechas, February 2013 (Spanish), http://www.dgeec.gov.py.

[14] Organización Panamericana de la Salud, Salud en las Americas. Volumen II-Paises, Organización Panamericana de la Salud, 2007 (Spanish), http://wwwl.paho.org/hia/vol2paises.html.

[15] World Health Organization, Global Tuberculosis Report 2002, World Health Organization, Geneva, Switzerland, 2002.

[16] World Health Organization, "Global tuberculosis control: surveillance, planning, financing," WHO Report, World Health Organization, Geneva, Switzerland, 2006.

[17] Dirección General de Estadística, "Encuestas y Censos: Atlas de las Comunidades Indígenas en el Paraguay," 2002, (Spanish), http://www.dgeec.gov.py/.

[18] World Health Organization, Global Health Observatory Data Repository, 2013, http://www.who.int/gho/en/.

[19] P. C. Basta, C. E. A. Coimbra Jr., J. R. Welch, L. C. Corra Alves, R. V. Santos, and L. A. Bastos Camacho, "Tuberculosis among the Xavante Indians of the Brazilian Amazon: an epidemiological and ethnographic assessment," Annals of Human Biology, vol. 37, no. 5, pp. 643-657, 2010.

[20] R. van Crevel, D. J. van Doorninck, J. E. van Ams, H. Tjon Kon Fat, S. G. S. Vreden, and J. W. M. van Der Meer, "Tuberculosis among Trio-Indians in Surinam," Nederlands Tijdschrift voor Geneeskunde, vol. 148, no. 9, pp. 425-429, 2004 (Dutch).

[21] P. C. Basta, C. E. A. Coimbra Jr., A. L. Escobar, R. V. Santos, L. C. C. Alves, and L. D. S. Fonseca, "Survey for tuberculosis in 
an indigenous population of Amazonia: the Suruí of Rondônia, Brazil," Transactions of the Royal Society of Tropical Medicine \& Hygiene, vol. 100, no. 6, pp. 579-585, 2006.

[22] M. N. Bóia, F. A. Carvalho-Costa, F. C. Sodré et al., “Tuberculosis and intestinal parasitism among indigenous people in the Brazilian Amazon region," Revista de Saúde Pública, vol. 43, no. 1, pp. 176-178, 2009.

[23] R. G. Baruzzi, V. L. Barros, D. Rodrigues, A. L. Souza, and H. Pagliaro, "Health and disease among Panará (Kreen-Akarôre) Indians in Central Brazil after twenty-five years of contact with our world, with an emphasis on tuberculosis," Cadernos de Saúde Pública, vol. 17, no. 2, pp. 407-412, 2001 (Portuguese).

[24] A. O. Sousa, J. I. Salem, F. K. Lee et al., "An epidemic of tuberculosis with a high rate of tuberculin anergy among a population previously unexposed to tuberculosis, the Yanomami Indians of the Brazilian Amazon," Proceedings of the National Academy of Sciences of the United States of America, vol. 94, no. 24, pp. 13227-13232, 1997.

[25] Instituto Paraguayo del Indígena (INDI), Base de Datos de Comunidades Indígenas, 2013, Instituto Paraguayo del Indígena (INDI), 2013 (Spanish), http://www.indi.gov.py/coms.php.

[26] R Development Core Team, R: A Language and Environment for Statistical Computing, R Foundation for Statistical Computing, Vienna, Austria, 2012, http://www.R-project.org/.

[27] A. L. Byers, H. Allore, T. M. Gill, and P. N. Peduzzi, "Application of negative binomial modeling for discrete outcomes: a case study in aging research," Journal of Clinical Epidemiology, vol. 56, no. 6, pp. 559-564, 2003.

[28] H. T. O. Davies, I. K. Crombie, and M. Tavakoli, "When can odds ratios mislead?” British Medical Journal, vol. 316, no. 7136, pp. 989-991, 1998.

[29] A. Cabello, M. Samudio, R. Galeano, A. Rojas Silva, M. Paez, and S. Ocampos, "Social determinants of health in indigenous population in the Paraguayan Chaco: a qualitative and quantitative study (Abstract)," in Proceedings of the 20th International Epidemiological Association World Congress of Epidemiology WebProgram, Anchorage, Alaska, USA, August 2014, https://wce.confex.com/wce/2014/webprogram/Paper3673.html. 


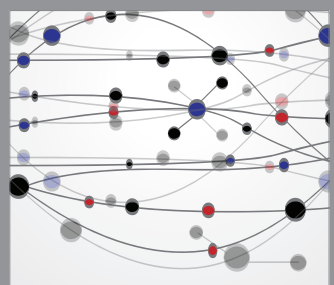

The Scientific World Journal
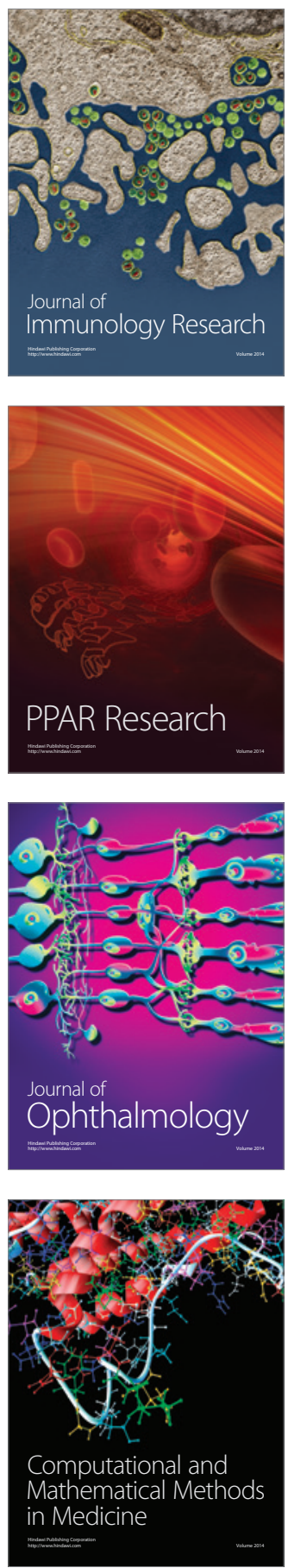

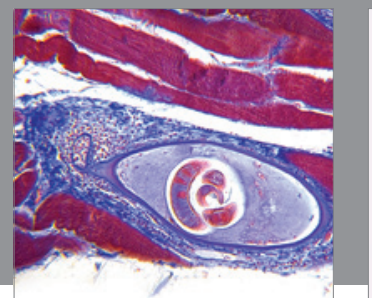

Gastroenterology

Research and Practice
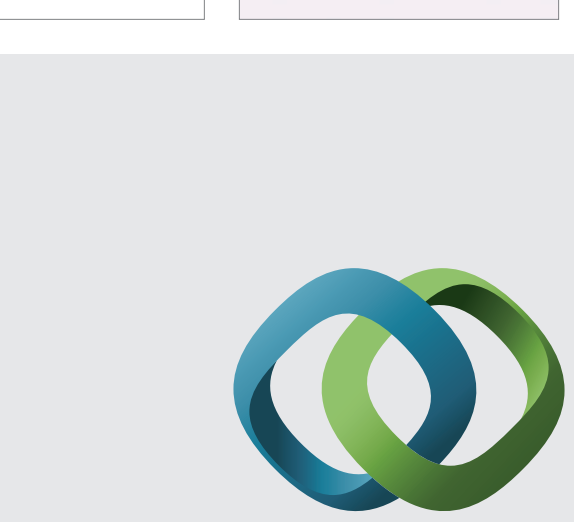

\section{Hindawi}

Submit your manuscripts at

http://www.hindawi.com
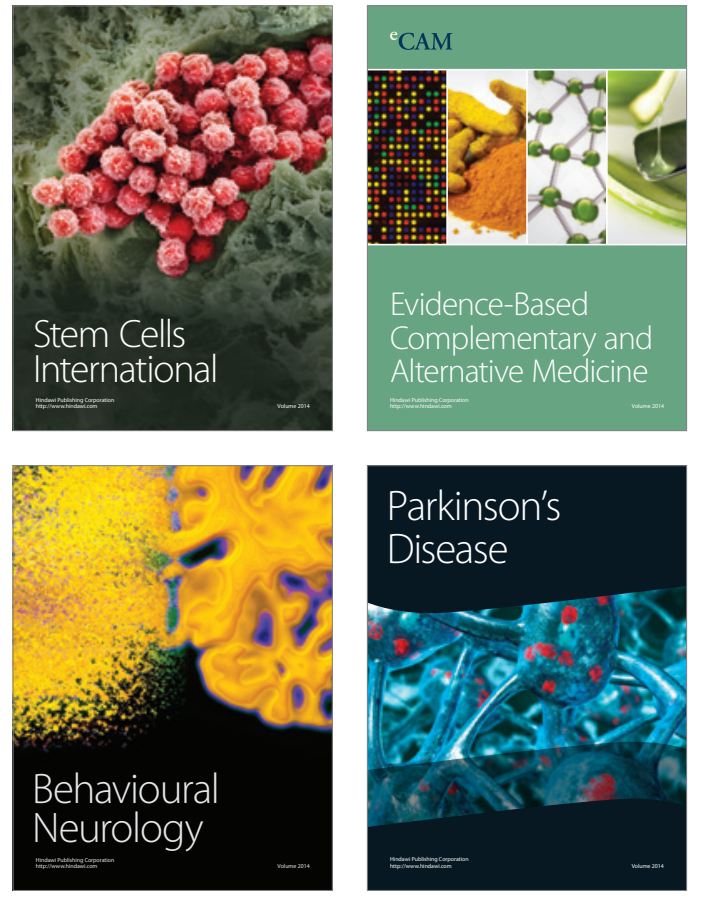
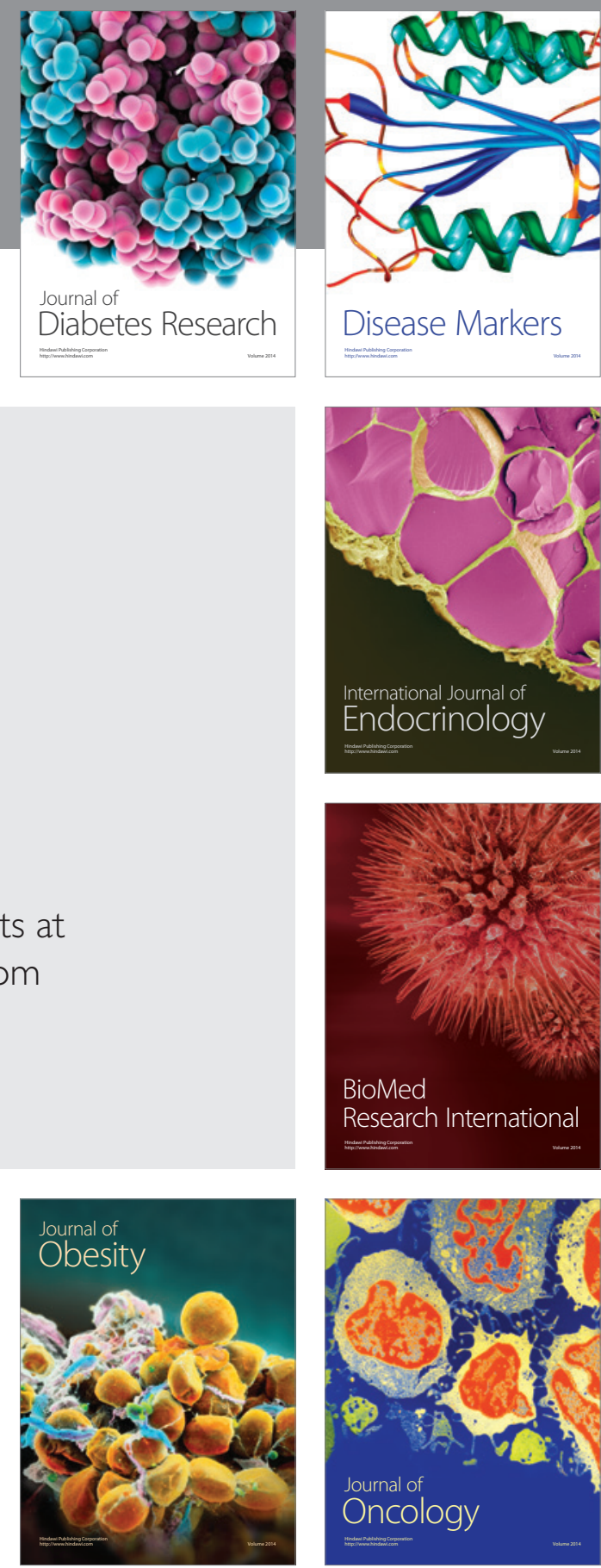

Disease Markers
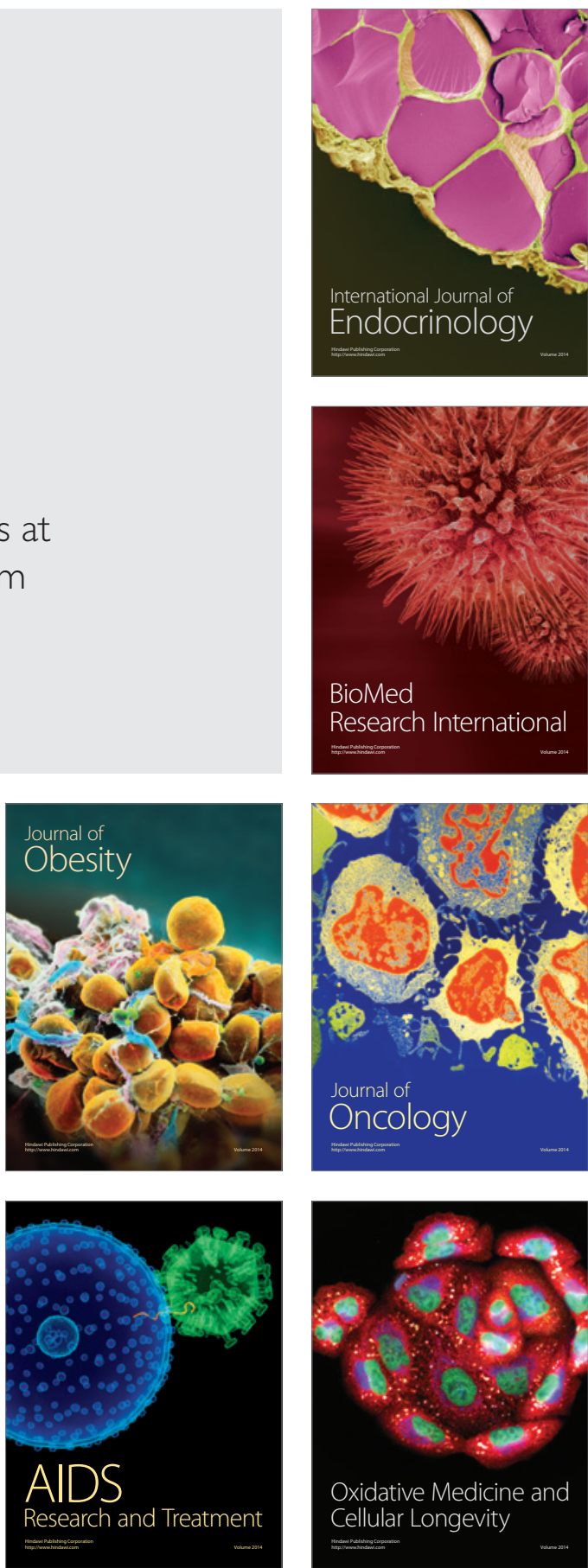